\title{
Cone penetration tests in dry and saturated Ticino sand
}

\author{
Max O. Kluger ${ }^{1,2}$ (D) $\cdot$ Stefan Kreiter $^{2}$ (D) $\cdot$ Florian T. Stähler $^{3}$ (D) $\cdot$ Majid Goodarzi $^{2,3} \cdot$ Tim Stanski $^{4} \cdot$ Tobias Mörz $^{2,3}$
}

Received: 11 July 2020 / Accepted: 19 February 2021 / Published online: 11 March 2021

(C) The Author(s) 2021

\begin{abstract}
It is commonly assumed that dry and saturated sands exhibit similar cone resistance-relative density relationships. Some studies pointed out that partial saturation and calcareous sands with considerable fines content are potential factors affecting these relationships. However, there is experimental evidence in Shaqour Bull Eng Geol Environ 66:59-70, (2006) that clean uncemented quartz sand may exhibit lower cone resistance in saturated conditions. The present study aims on contributing towards better understanding the effect of water saturation on cone resistance in sand. For this purpose, Ticino sand samples were prepared dry and saturated in a calibration chamber and cone penetration tests were performed over a wide range of relative densities and at two consolidation stresses. Overall, it was observed that dry and saturated samples exhibited similar cone resistances. Only slightly higher cone resistances were observed for dry samples at the lower consolidation stress. Two anomalous samples, which were tested dry at medium relative density, were found to exhibit way higher cone resistances than expected from published cone resistance-relative density relationships. The Young's modulus was observed to be proportional to cone resistance and independent of whether a sample was tested dry or saturated, being therefore considered as more robust soil property for cone resistance relationships.
\end{abstract}

Keywords Cone penetration test $\cdot$ Water saturation $\cdot$ Dry sand $\cdot$ Calibration chamber $\cdot$ Relative density $\cdot$ Young's modulus

\section{Introduction}

The cone penetration test is a widely applied subsoil investigation method (ASTM D5778 2012; DIN EN ISO 2247612013 ) and numerous authors have discussed the factors that influence cone penetration test results (Robertson 2009; Robertson and Campanella 1983; Schmertmann 1978). Only few studies investigated whether or not dry and

Max O. Kluger

max.kluger@waikato.ac.nz

Stefan Kreiter

skreiter@uni-bremen.de

Florian T. Stähler

fstaehler@geo-engineering.org

1 School of Science, University of Waikato, Hamilton, New Zealand

2 MARUM-Center for Marine Environmental Sciences, University of Bremen, Bremen, Germany

3 Geo-Engineering.org GmbH, Bremen, Germany

4 Department of Geosciences, University of Bremen, Bremen, Germany saturated sands exhibit different cone penetration test results (e.g. Giretti et al. 2018; Pournaghiazar et al. 2013). The saturation condition in sands may vary between dry, partially, and fully saturated. It is commonly accepted that pore water itself does not significantly influence the critical friction angle of glass beads (Dai et al. 2016; Skinner 1969). Following the concept of cavity expansion theory, the critical friction angle directly influences the calculation of cone resistance (Silva et al. 2006; Suzuki and Lehane 2015). Thus, pore water should not have any effect on cone resistance in theory. This view was supported by numerous experimental studies, which did not find significant difference in cone resistance between dry and saturated conditions (Almeida et al. 1991; Baldi et al. 1982; Bonita 2000; Pournaghiazar et al. 2013).

Differences in cone resistance were observed for partially saturated sands (Hryciw and Dowding 1987; Pournaghiazar et al. 2013). The authors argued that suction in the water menisci around the grain contacts were a dominant factor that increased cone resistance in partially saturated sands. Significant differences in cone resistances between dry and saturated conditions were also observed by Shaqour (2006) who performed cone penetration tests in quartz sand as well as in calcareous sand. For both sand types, the cone 
resistances measured in dry samples were considerably higher than in saturated samples. Smaller increases between dry and saturated samples were reported by Giretti et al. (2018) who performed cone penetrations in centrifuge tests in carbonate sand. The pronounced decrease in cone resistance due to water saturation contradicts the established view about the influence of saturation condition on cone resistance. Shaqour (2006) performed tests at high relative densities and so far, it is unknown if the observations made by the author would hold true for lower relative densities.

The present study aims on contributing towards better understanding the effect of saturation on cone resistance in sand. For this purpose, dry and saturated Ticino sand samples were prepared and cone penetration tests were performed over a wide range of relative densities and at two consolidation stresses.

\section{Materials and methods}

\section{Physical properties of Ticino sand}

The Ticino sand used in this study is a well-studied reference material from northern Italy (Butlanska et al. 2014; Fioravante and Giretti 2015; Kulhawy and Mayne 1990). It is a uniformly graded, medium-coarse to coarse sand $\left(d_{50}=0.6 \mathrm{~mm}\right)$ with neglectable fines content. Ticino sand is sub-rounded to angular, has a particle density of $\rho_{\mathrm{s}}=2680 \mathrm{~kg} / \mathrm{m}^{3}$, and minimum and maximum void ratios of $e_{\min }=0.58$ and $e_{\max }=0.93$. Main mineral components are feldspar (65\%) and quartz (30\%) with a minor fraction of mica.

\section{Equipment and testing procedure of cone penetration tests}

The MARUM calibration chamber (MARCC) was used for performing cone penetration tests in the laboratory under controlled stresses and relative densities (Fleischer et al. 2016; Goodarzi et al. 2018; Stähler et al. 2018a; Stähler et al. 2018b) (Fig. 1). The samples were $30 \mathrm{~cm}$ in diameter and $54.5 \mathrm{~cm}$ in height. The chamber was equipped with a highresolution piezocone having a diameter of $12 \mathrm{~mm}$, which corresponds to a sample to cone diameter ratio of $R_{D}=25$. The sample was surrounded by a flexible latex membrane and was confined by a sinter metal filter at the top and a water-filled latex cushion at the bottom of the sample. Vertical and horizontal stresses as well as the pore water pressure were controlled by syringe pumps. Axial strain, $\varepsilon_{\mathrm{a}}$, was calculated from volumetric change in the water-filled latex cushion, $\Delta V_{\mathrm{lc}}$, following Eq. 1 .

$\varepsilon_{\mathrm{a}}=\frac{\Delta l}{l_{0}}=\frac{\frac{\Delta V_{\mathrm{cl}}}{A}-l_{0}}{l_{0}}$ where $l_{0}, \Delta l$, and $A$ are initial length, difference in length due to axial strain, and cross-sectional area of the sample, respectively. Two different methods were used to estimate horizontal strain. In the first method, changes in volume of the cell water surrounding the sample, $\Delta V_{\mathrm{cw}}$, were used as a measure of horizontal strain, $\varepsilon_{\mathrm{h}, \mathrm{cw}}$, following Eq. 2.

$\Delta V_{\mathrm{cw}}=\Delta V=V_{1}-V_{0}=\frac{\pi d_{1}^{2}}{4} \cdot h_{1}-\frac{\pi d_{0}^{2}}{4} \cdot h_{0}$

where $\mathrm{V}, d$, and $h$ are the volume, diameter, and height of the sample that experience strain between two states, as denoted by subscripts 0 and 1 . After rearranging the equation and some simplifications, one may write Eq. 2 as

$d_{1}=d_{0}+2 \sqrt{\frac{\Delta V_{\mathrm{cw}}}{\pi h_{0} h_{1}}}$

Horizontal strain can then be calculated from Eq. 4 .

$\varepsilon_{\mathrm{h}, \mathrm{cw}}=\frac{\Delta d}{d_{0}}=\frac{d_{1}-d_{0}}{d_{0}}$

In the second method, three circumferential displacement sensors, placed at 15,25 , and $35 \mathrm{~cm}$ depths from the top of the sample, were used as an additional measure of horizontal strain, $\varepsilon_{\mathrm{h}, \mathrm{ds}}$ (Eqs. 5 and 6).

$\varepsilon_{\mathrm{h}, \mathrm{ds}, n}=\frac{U_{n, 1}-U_{n, 0}}{U_{n, 0}}$

$\varepsilon_{\mathrm{h}, \mathrm{ds}}=\frac{\sum_{n=1}^{3} \varepsilon_{\mathrm{h}, \mathrm{ds}, n}}{3}$

where $U$ is the perimeter of the sample measured by one of the three circumferential displacement sensors (denoted with index $n$ ).

Ticino sand samples were tested dry and saturated at initial relative densities of $0.4 \leq D_{\mathrm{R}, \mathrm{i}} \leq 1.0$ and at two vertical effective consolidation stresses, $\sigma_{\mathrm{vc}}^{\prime}$, of 100 and $200 \mathrm{kPa}$ using a lateral earth pressure coefficient of $K_{0}=0.45$. The two vertical effective consolidation stresses considered in the present study correspond to depths of 10 and $20 \mathrm{~m}$ below ground, which are relevant depths for deep foundation problems (Haiderali et al. 2015). Specifications of all cone penetration tests are provided in Table 1. The testing procedure consisted of five phases as follows.

Phase 1-Sample preparation: A latex membrane was placed at the inside of a sample mould. Samples were prepared using the sand curtain pluviation method. The pluviation device used in the present study was similar to Baldi et al. (1981) and had an adjustable aperture size that controlled the flow rate of sand particles. The flow rate is known to be proportional to the relative density of the sample (Lagioia et al. 2006). The initial relative density of the sample, $D_{\mathrm{R}, \mathrm{i}}$, was 


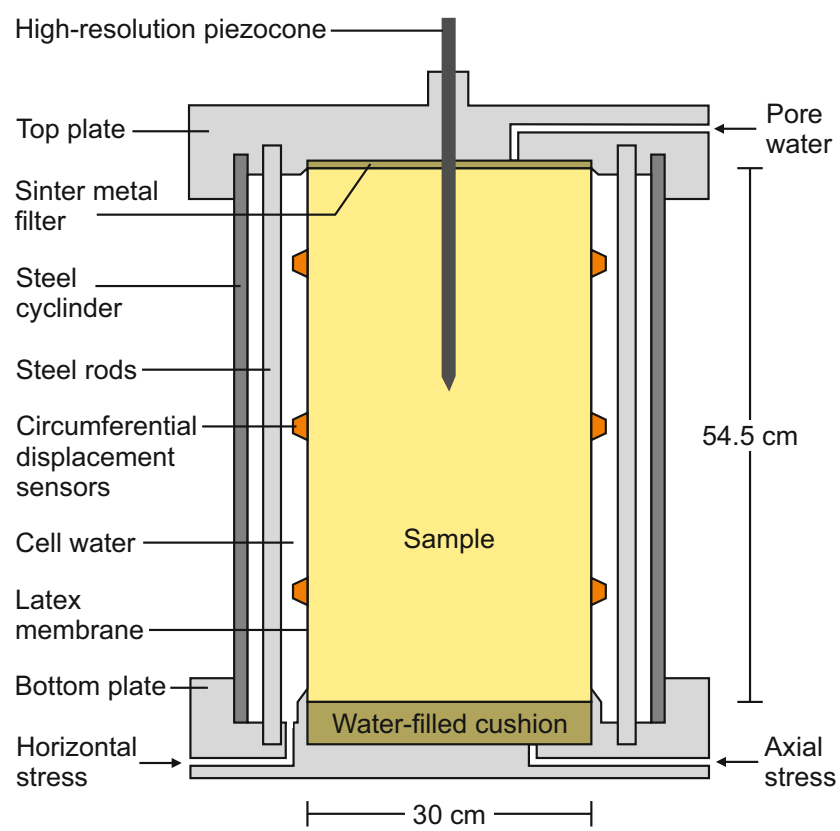

Fig. 1 Schematic representation of the MARUM calibration chamber used for cone penetration tests

calculated from the sample's dry mass and the inner volume of the sample mould and taking the latex membrane into account.

Phase 2-Pre-consolidation: A vacuum of $p=-10 \mathrm{kPa}$ was applied in the pore space of the sample. The sample mould was removed. Then the three circumferential displacement sensors were attached to the latex membrane before the chamber was assembled and cell water was filled into the chamber. An initial isotropic effective stress of $\sigma^{\prime}=10 \mathrm{kPa}$ was applied in order to stabilize the sample. Finally, the penetrometer was pushed into the top of the sample until the entire cone was in contact with the sample. Samples were either kept dry or were saturated with deaerated and demineralized water (Table 1). Skempton's $B$ coefficients of $\geq 0.95$ were achieved from saturation tests for all saturated samples. During the saturation test, an isotropic stress of $\sigma=$ $210 \mathrm{kPa}$ and a backpressure of $\Delta u=200 \mathrm{kPa}$ were applied, resulting in an isotropic effective stress of $\sigma^{\prime}=10 \mathrm{kPa}$. The saturation was checked by increasing vertical, $\sigma_{\mathrm{v}}$, and horizontal stresses, $\sigma_{\mathrm{h}}$, by $30 \mathrm{kPa}$ (ASTM D7181 2020). Afterwards, both normal stresses were reduced back to $\sigma=$ $210 \mathrm{kPa}$.

Phase 3-Consolidation: The isotropic effective stress of the samples was increased in one step from $\sigma^{\prime}=10 \mathrm{kPa}$ to match the desired horizontal effective consolidation stress, $\sigma_{\text {hc }}^{\prime}$, being either 45 or $90 \mathrm{kPa}$. Afterwards, the vertical effective stress was increased in one step to match the desired vertical effective consolidation stress, being either 100 or $200 \mathrm{kPa}$. Samples were anisotropically consolidated for 90 min (Table 1). During consolidation, the axial, $\varepsilon_{\mathrm{a}}$, and horizontal strains, $\varepsilon_{\mathrm{h}, \mathrm{cw}}$, of the sample were recorded (Fig. 2a).

Phase 4-Lateral compression test: All cone penetration tests were performed under simulated field boundary condition (BC5), adopting the approach of Huang and Hsu (2005). The concept of simulated field boundary condition assumes that the sample is placed in an infinite soil volume with known horizontal stiffness. In chambers with small sample to cone diameter ratios, as in this study, a sample with constant horizontal stress boundary would have experienced more horizontal strain during the cone penetration test than an equivalent field test. In order to keep the horizontal stress and horizontal

Table 1 Specifications of cone penetration tests

\begin{tabular}{|c|c|c|c|c|c|c|c|c|c|}
\hline Reference & Test no. & Test condition & $\begin{array}{l}\sigma_{\mathrm{v}}^{\prime} \\
\mathrm{kPa}\end{array}$ & $\begin{array}{l}\sigma_{\mathrm{h}}^{\prime} \\
\mathrm{kPa}\end{array}$ & $\begin{array}{l}q_{\mathrm{cs}} \\
\mathrm{MPa}\end{array}$ & $D_{\mathrm{R}, \mathrm{i}}$ & $D_{\mathrm{R}, \mathrm{pc}}$ & $D_{\mathrm{R}, \mathrm{c}}$ & $D_{\mathrm{R}, \mathrm{lc}}$ \\
\hline \multirow[t]{3}{*}{ Present study } & 1 & \multirow[t]{3}{*}{ Saturated } & \multirow[t]{3}{*}{100} & 45 & 13.09 & 0.686 & 0.706 & 0.710 & 0.719 \\
\hline & 2 & & & 45 & 15.13 & 0.793 & 0.812 & 0.827 & 0.838 \\
\hline & 3 & & & 45 & 18.95 & 0.943 & 0.960 & 0.965 & 0.970 \\
\hline \multirow[t]{3}{*}{ Present study } & 4 & \multirow[t]{3}{*}{ Dry } & \multirow[t]{3}{*}{100} & 45 & 10.52 & 0.407 & 0.425 & 0.432 & 0.442 \\
\hline & 5 & & & 45 & 17.99 & 0.800 & 0.826 & 0.830 & 0.878 \\
\hline & 6 & & & 45 & 21.18 & 0.923 & 0.938 & 0.944 & 0.952 \\
\hline \multirow[t]{7}{*}{ Stähler et al. (2018a) } & 7 & \multirow[t]{7}{*}{ Saturated } & \multirow[t]{7}{*}{200} & 90 & 16.17 & 0.638 & 0.661 & 0.662 & 0.668 \\
\hline & 8 & & & 90 & 24.71 & 0.756 & 0.772 & 0.774 & 0.780 \\
\hline & 9 & & & 90 & 25.46 & 0.786 & 0.807 & 0.819 & 0.826 \\
\hline & 10 & & & 90 & 31.37 & 0.876 & 0.895 & 0.896 & 0.901 \\
\hline & 11 & & & 90 & 30.29 & 0.886 & 0.899 & 0.900 & 0.918 \\
\hline & 12 & & & 90 & 32.22 & 0.900 & 0.918 & 0.920 & 0.925 \\
\hline & 13 & & & 90 & 34.14 & 0.931 & 0.949 & 0.951 & 0.957 \\
\hline \multirow[t]{3}{*}{ Present study } & 14 & \multirow[t]{3}{*}{ Dry } & \multirow[t]{3}{*}{200} & 90 & 22.53 & 0.564 & 0.592 & 0.597 & 0.606 \\
\hline & 15 & & & 90 & 24.57 & 0.712 & 0.736 & 0.740 & 0.748 \\
\hline & 16 & & & 90 & 31.24 & 0.883 & 0.906 & 0.910 & 0.918 \\
\hline
\end{tabular}


strain as similar as possible to field conditions, the increase in horizontal strain was compensated by increasing the horizontal stress of the sample. The unique stress-strain relationship for this compensation was obtained from a lateral compression test preceding the cone penetration test (Fig. 2a, b). The horizontal effective stress was increased at a constant rate of $\dot{\sigma}_{\mathrm{h}}^{\prime}$ $=10 \mathrm{kPa} /$ min until a horizontal strain of $\varepsilon_{\mathrm{h}, \mathrm{ds}}=0.08 \%$ was reached. Similar to Huang and Hsu (2005), the real-time data from the circumferential displacement sensors were used to determine the horizontal strain during the lateral compression test. The Young's modulus, $E$, was obtained at horizontal strain of $0.05 \leq \varepsilon_{\mathrm{h}, \mathrm{ds}} \leq 0.07 \%$, being visualized in Fig. $2 \mathrm{~b}$. A unique horizontal stress-horizontal strain relationship was obtained by fitting a fifth-degree polynomic function to the data. The horizontal strain was reduced back following this function.

Phase 5-Cone penetration test: The cone penetrometer was pushed into the sample at a constant penetration rate of $\dot{s}=20 \pm 0.3 \mathrm{~mm} / \mathrm{s}$, while measuring cone resistance, $q_{\mathrm{c}}$, at a sampling rate of $f=20 \mathrm{~Hz}$. The simulated field boundary condition was established by using the unique horizontal stress-horizontal strain relationship obtained during the lateral compression test in phase 4 . While the cone was pushed into the sample, the horizontal strain, $\varepsilon_{\mathrm{h}, \mathrm{ds}}$, measured from the circumferential displacement sensors determined the increase in horizontal stress in real time according to the unique horizontal stress-horizontal strain relationship. A steady-state cone resistance, $q_{\mathrm{cs}}$, was determined by averaging the cone resistance data within the depth interval between 180 and $320 \mathrm{~mm}$. A standard deviation was calculated for every steady-state cone resistance value.

Changes in relative densities were continuously monitored after phases 1 to 4 , resulting in relative densities after sample preparation, $D_{\mathrm{R}, i}$, pre-consolidation, $D_{\mathrm{R}, \mathrm{pc}}$, consolidation phase $D_{\mathrm{R}, \mathrm{c}}$, and lateral compression test, $D_{\mathrm{R}, \mathrm{lct}}$.

\section{Consistency of cone penetration tests}

The monitoring of relative density during the testing procedure was important to solely relate changes in cone resistances to the saturation condition of the sample. The relative densities of all samples slightly increased during phases 1 to 4 for all samples (Table 1, Fig. 2c). The cumulative increases in relative densities were small, being commonly between 0.02 and 0.04 . Only test no. 5 showed a higher cumulated increase in relative density of c. 0.08 . This shows that the four phases, preceding the cone penetration test, did only slightly influence the relative density of individual samples.

The stress and strain paths during consolidation and lateral compression tests were monitored for all samples; two typical examples, one for each consolidation stress, are provided in Fig. 2a. The increase in axial and horizontal strain, measured from the cell water volume, $\varepsilon_{h, c w}$, during consolidation, was small in both tests. During the lateral compression test,
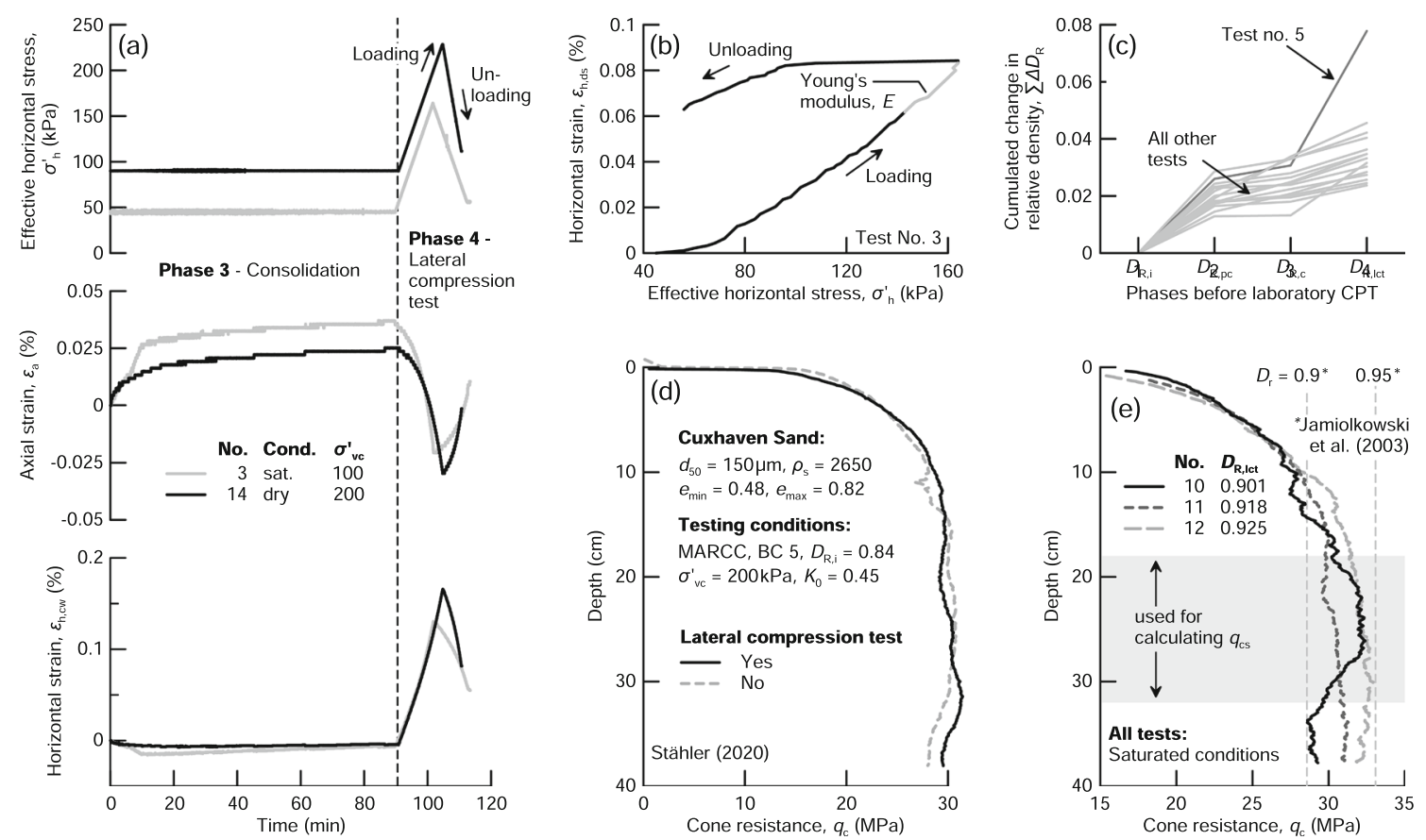

Fig. 2 Quality of cone penetration tests. (a) Typical consolidation behaviour of samples tested in the MARUM calibration chamber; (b) example of a lateral compression test; (c) changes in relative density due to the four stages before cone penetration testing; (d) example

showing the influence of lateral compression test on cone resistance; and (e) three cone resistance curves showing repeatability of chamber tests. sat., saturated 
horizontal stress was increased resulting in a significant increase in horizontal strain, being accompanied by a small decrease in axial strain. After horizontal strain was reduced back to the state just before penetration, some permanent horizontal strain remained. The horizontal strain measured from the circumferential displacement sensors, $\varepsilon_{\mathrm{h}, \mathrm{ds}}$, commonly remained constant during the beginning of the unloading part of the lateral compression test (Fig. 2b), which is believed to be a result of limitations in the circumferential displacement sensors used in this study. The permanent horizontal strain, $\varepsilon_{\mathrm{h}, \mathrm{ds}}$, measured after the lateral compression test was similar with the horizontal strain obtained from the cell water, $\varepsilon_{\mathrm{h}, \mathrm{cw}}$.

The amount of horizontal strain (determined from both cell water and circumferential displacement sensors) due to the lateral compression test lay well above the elastic soil behaviour range for Ticino sand (Yamashita et al. 2000). The influence of the lateral compression test on cone resistance has been investigated for clean quartz sand from Northern Germany (Stähler 2020) (Fig. 2d). The author performed cone penetration tests using similar testing conditions than those of the present study (e.g., boundary condition, effective consolidation stress, relative density) and showed that for clean quartz sand, the lateral compression test does not have a significant effect on cone resistance. This observation may be transferred to Ticino sand because it has been shown by Jamiolkowski et al. (2003) that dry Ticino sand exhibits similar cone resistance-relative density relationships than clean quartz sands. It may be concluded that the lateral compression test does induce an overconsolidation of the sample, which, although not large enough for having an effect on cone resistance in the case of the present study, should be avoided in future projects dealing with cone penetration tests in chambers having small sample to cone diameter ratios. The authors recommend that for a specific soil, one should establish the horizontal stress-horizontal strain relationship based on a number of lateral compression tests on samples having relative densities and consolidation stresses relevant to the study. These tests should be performed prior to the subsequent laboratory cone penetration tests in order to avoid any overconsolidation in the sample to happen.

The repeatability of samples tested in this study was investigated by comparing cone resistance against depth curves for similar relative densities at the same effective consolidation stress (Fig. 2e). It can be observed that the three cone resistance curves are of similar shape and plot between the cone resistance isolines calculated from the relationship of Jamiolkowski et al. (2003). The overall heterogeneity of samples tested in this study can be assessed by comparing the cone resistance variability with respect to consolidation stress, relative density, and saturation conditions (Fig. 3). The cone resistance initially increased with penetration depth in all tests, being commonly associated with the top boundary of the calibration chamber (Almeida et al. 1991; Arroyo et al. 2011). A reasonable plateau was observed within the steady-state interval for most tests. The general shape of the cone resistance curves was found to be of similar quality than curves from other studies (Almeida et al. 1991; Ghionna and Jamiolkowski 1991; Huang and Hsu 2005). By plotting the steady-state cone resistances together with their respective standard deviations against relative density (Fig. 4), it could be observed that the variability in cone resistances decreased towards higher relative density and lower consolidation stress. No clear dependency between saturation condition and variability in cone resistance could be observed. Some samples (e.g., test no. 8 , highlighted in Fig. 4) exhibited higher variability in cone resistance. Higher variability in cone resistance in medium and loose samples may be a result of inhomogeneous arrangements of sand particles caused by, e.g., layering and density contrasts, being commonly more pronounced at lower relative densities (Gade et al. 2015; Hariprasad et al. 2016).

In calibration chambers with small sample to cone diameter ratios, such as the one used in the present study, boundary artefacts are a major factor influencing cone resistance (Baldi et al. 1981). The steady-state cone resistances obtained in the present study for saturated Ticino sand samples were plotted together with the cone resistance-relative density relationship of Jamiolkowski et al. (2003), having been derived from dry Ticino sand samples tested in a large calibration chamber. The comparison shows that probably no significant boundary artefacts were induced as cone resistance values of saturated Ticino sand samples plotted close to the relationship of Jamiolkowski et al. (2003).

\section{Cone resistances of dry and saturated samples}

The influence of saturation was studied by comparing samples tested dry with those tested in saturated condition at a similar relative density (Fig. 3). For samples no. 3 and 6, tested at the lower consolidation stress of $\sigma_{\mathrm{vc}}^{\prime}=100 \mathrm{kPa}$, a clear difference in cone resistance between dry and saturated condition could be observed (Fig. 3a). The saturated sample exhibited a lower cone resistance than the dry sample and was well smaller than would have been expected from the relationship of Jamiolkowski et al. (2003) (dashed vertical lines in Fig. 3). The other two samples tested at the low consolidation stress matched well with the relationship without showing a difference between dry and saturated condition. Medium dense samples no. 7 and 14, tested at the higher consolidation stress of $\sigma_{\mathrm{vc}}^{\prime}=200 \mathrm{kPa}$, exhibited a large difference in cone resistance. The dry sample by far exceeded the value expected from the relationship of Jamiolkowski et al. (2003), whereas the saturated sample only slightly exceeded the expected value (Fig. 3b). For the other samples tested at the higher 

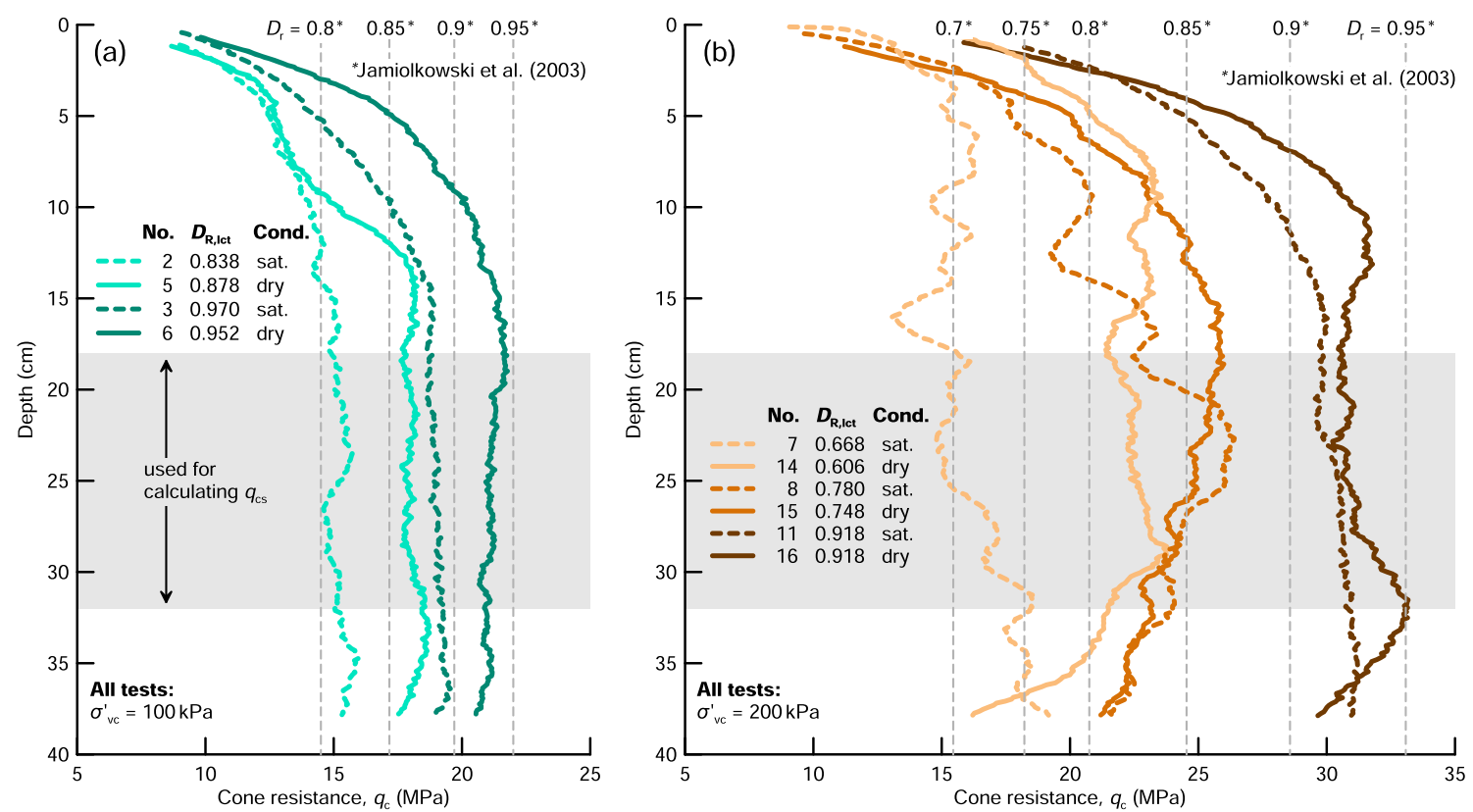

Fig. 3 Typical cone resistance curves for dry and saturated Ticino sand

consolidation stress, the cone resistance curves of dry and saturated samples did not exhibit significant differences.

The dry and saturated samples were further analyzed by plotting their steady-state cone resistances against their relative density for both consolidation stresses and comparing them with the relationship of Jamiolkowski et al. (2003) (Fig. 4). At the low consolidation stress, the samples fitted well with the published relationship, except for one anomalous sample, which was reconstituted to a medium-dense dry condition (see sample no. 4 in Fig. 4). The steady-state cone resistance of this

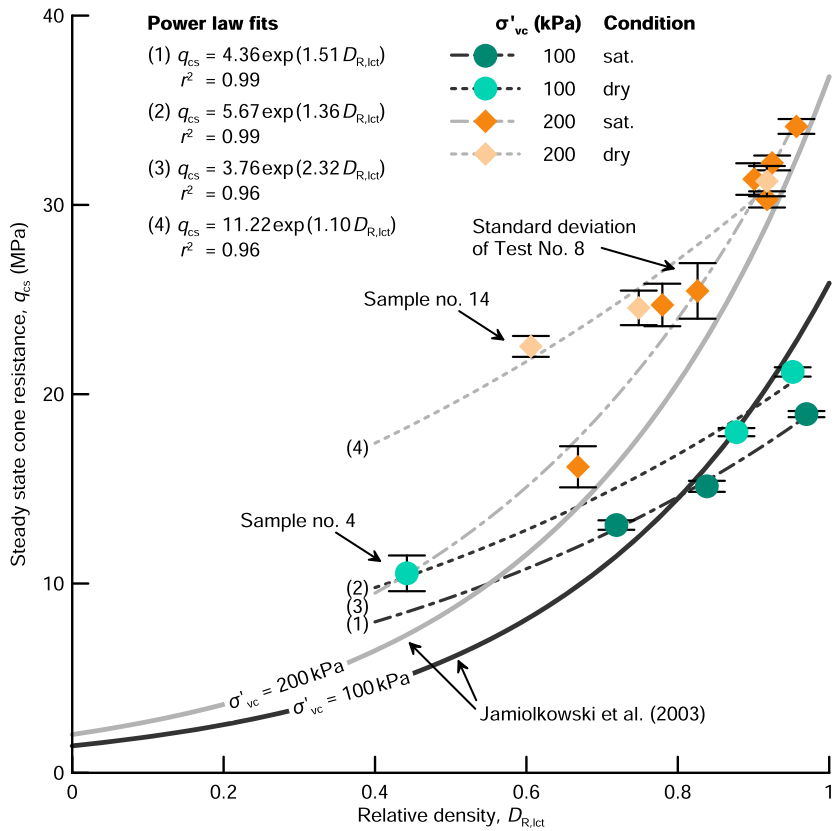

Fig. 4 Relationships between steady-state cone resistance and relative density. Vertical error bars represent standard deviations for individual tests sample exceeded by far the value expected from the relationship of Jamiolkowski et al. (2003). At the high consolidation stress, most samples followed the relationship of Jamiolkowski et al. (2003), although slightly higher steady-state cone resistances were measured for all samples. One clearly anomalous sample was recognized for the high consolidation stress exceeding by far the expected value from the relationship of Jamiolkowski et al. (2003) (see sample no. 14 in Fig. 4)

The samples could be reasonably well fitted to power law functions of the shape proposed by Baldi et al. (1982) (see fit curves 1-4 in Fig. 4). Based on the fitted functions, samples tested dry tended to have slightly higher steady-state cone resistances than saturated samples for the lower consolidation stress considered in the present study. For higher consolidation stress, the difference between dry and saturated samples was less pronounced and was only detectable at medium relative density. Note that the conclusions made based on the fitted functions were mainly supported by the two anomalous samples (nos. 4 and 14), which had a very high influence on the shape of the fitted functions. Without considering those two anomalous samples, the fitted functions would have been very well in accordance with the relationships of Jamiolkowski et al. (2003). It is therefore reasonable to conclude that in the present study, the overall influence of saturation condition is small and that only two samples reconstituted to medium-dense dry conditions exhibited pronounced higher cone resistances than expected.

Available studies about the influence of saturation condition (dry vs. saturated) on cone resistance are summarized in Table 2. For quartz sands, the effects of saturation condition on steady-state cone resistance were commonly reported to be neglectable (Almeida et al. 1991; Baldi et al. 1982; Bonita 2000; Porcino and Marcianò 2010; Pournaghiazar et al. 
2013). Shaqour (2006) reported very high differences between dry and saturated quartz and calcareous sands, with cone resistances of dry samples being up to c. $750 \%$ higher than saturated samples. Giretti et al. (2018) performed centrifuge cone penetration tests on carbonate sand and found a small increase in cone resistance in dry samples of up to c. $20 \%$ compared with dry samples. The relatively small difference between dry and saturated samples reported in the present study is of similar magnitude than that reported by Giretti et al. (2018).

In engineering practice, the lateral stiffness and shear strength of the soil are commonly more important soil properties than relative density. Therefore, the Young's modulus has been used as soil property to describe changes in cone resistance in the past (Jamiolkowski et al. 2003; Sadrekarimi 2016; Schmertmann 1978). The advantage of using the Young's modulus rather than relative density as soil property can be observed in Fig. 5, in which the Young's modulus obtained during the lateral compression tests was plotted against the steady-state cone resistance for all testing conditions. It was observed that the Young's modulus linearly increased with steady-state cone resistance independently of whether the sample was tested dry or saturated. The Young's modulus could therefore be implemented as better and more robust soil property for the characterization of sand by cone penetration tests.

\section{Possible influencing factors why dry and saturated sand may exhibit different soil behaviour}

In the present study, it was observed that two anomalous samples, tested dry at medium relative density, exhibited way higher cone resistances than expected from the relationship of Jamiolkowski et al. (2003). Possible influencing factors are summarized below.

Suction due to partial saturation is known to increase cone resistance. Hryciw and Dowding (1987) showed that already a neglectable degree of saturation $\left(\mathrm{S}_{\mathrm{r}} \approx 0\right)$ can cause suction and, thus, significantly increases the cone resistance in Ottawa sand. In the present study, Ticino sand was oven-dried and then cooled to room temperature in a controlled environment of low humidity. Samples were then pluviated into the chamber. It is therefore unlikely that the oven-dried samples tested in the present study exhibited any suction pressure due to partial saturation.

Furthermore, grain size distribution has a significant effect on cone resistance (Lunne et al. 1997). During the penetration, the sand surrounding the cone may undergo a certain degree of grain crushing and grain abrasion, which might be enhanced by wetting, consolidation stress, and relative density (Dano et al. 2018; Oldecop and Alonso 2003). Bellotti et al.

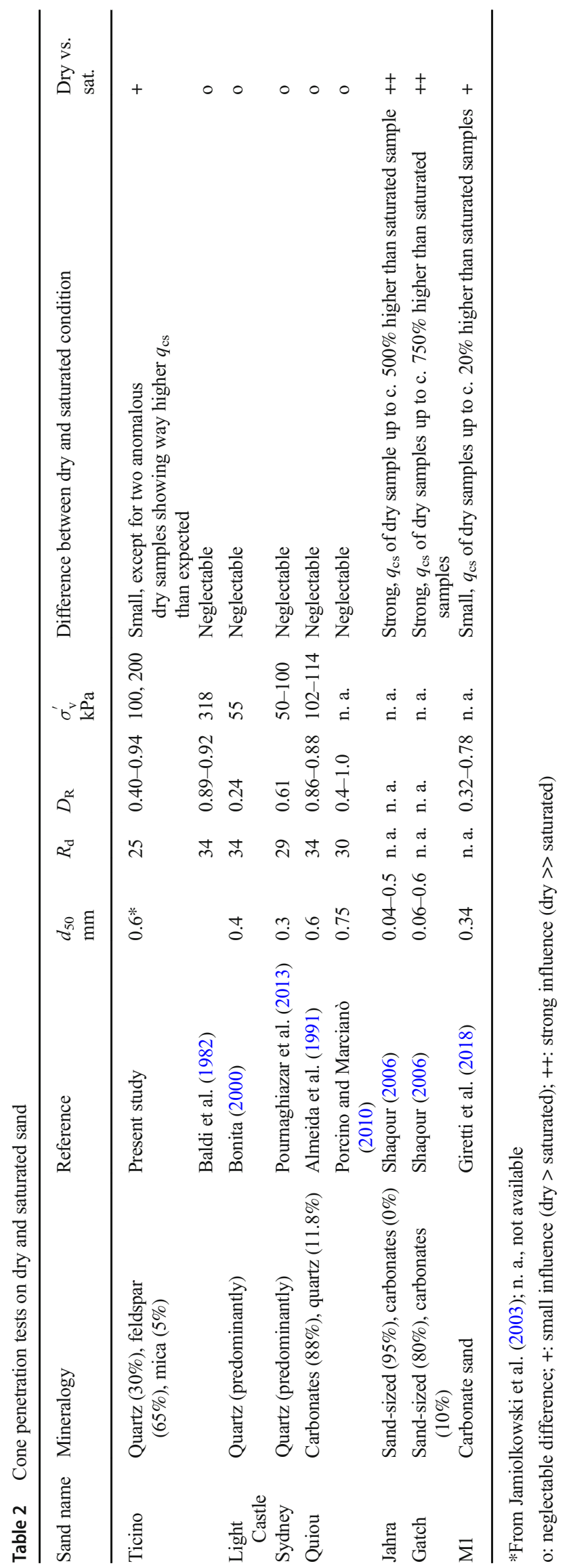


(1992) investigated the crushability potential of Ticino sand using an oedometer apparatus that was modified for high stress levels and found a crushability threshold of c. $20 \mathrm{MPa}$ beyond which extensive grain crushing started to occur. Furthermore, the authors studied the crushability of Ticino sand in a cone penetration test calibration chamber and found a direct correlation between crushing amount and cone resistance. However, the fact that the difference in cone resistance was only observed at medium relative density at both consolidation stresses would rather contradict this influencing factor in the present study.

Not fully drained conditions caused by fast penetration of the cone and/or low permeability soils could induce excess pore pressure within the saturated sample, eventually reducing the cone resistance (Jamiolkowski et al. 2003). This process could have played a role in the investigation of Shaqour (2006), who performed cone penetration tests in sands with considerable fines content. The samples tested in the present study are composed of uniformly graded medium-coarse to coarse Ticino sand. In such sand types, excess pore pressure is considered to dissipate immediately due to their high permeability (Lunne et al. 1997; Robertson 2010) making it less likely that in our study excess pore pressure played a role in the reduction of cone resistance due to saturation.

Studies with glass spheres of the same size found no influences of water on the shear strength of sand (Dai et al. 2016; Skinner 1969), but even a small deviation in particle shape from a perfect sphere significantly affects the strength and internal mechanical behaviour of granular materials (Mirghasemi et al. 2002). Particle rolling is less pronounced in assemblies with non-spherically shaped particles and changes in particle friction are probably more important than in assemblies with perfect spheres. Classical hydrodynamic or elastic-hydrodynamic lubrication, as it occurs in bearings,

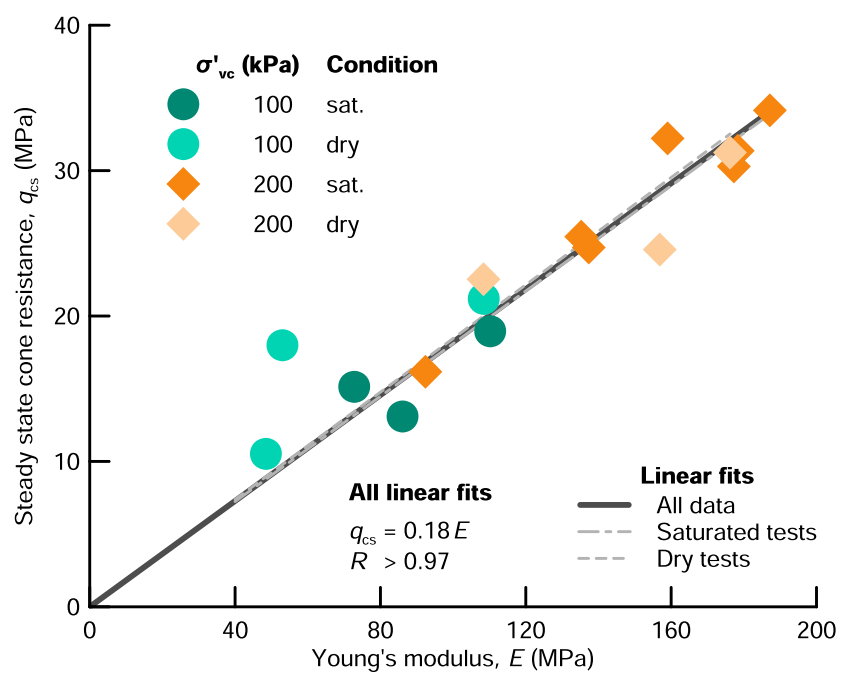

Fig. 5 Relationship between steady-state cone resistance and Young's modulus does most likely not occur in saturated sand, since water has a low viscosity and, thus, the contact stresses are high and the velocities are relatively small (Hamrock et al. 2004). Boundary lubrication caused by the chemical and physical interaction of the solid and the fluid may be the cause for the observed differences in steady-state cone resistance, even though only bulk mechanical properties were determined in the present study. Other studies of bulk properties, such as direct shear tests, found that dry sand does exhibit higher peak friction angle than wet sand (Tiwari and Al-Adhadh 2014a, b). A comprehensive model for the influence of water on the particle interactions and bulk properties is still lacking.

Slightly higher cone resistances, observed for dry samples at the lower consolidation stress, may be best explained by boundary lubrication. However, the influencing factors described above are not capable to fully explain the observed differences in cone resistance for the two anomalous samples. It can only be guessed that the high cone resistances measured during those two tests arose from problems with sample preparation or testing procedure. Future research is needed in order to better quantify the processes leading to increases in cone resistance in dry samples.

\section{Conclusion}

A number of cone penetration tests were performed in a calibration chamber with small sample to cone diameter in order to investigate whether or not saturated and dry sand exhibits similar cone resistance. Ticino sand samples were tested either saturated or dry at relative densities, ranging between medium to very dense, and two different consolidation stresses. The results were compared with relative density-cone resistance relationship of Jamiolkowski et al. (2003). The following conclusions were made:

- The overall difference in cone resistance between dry and saturated samples was small. At the lower consolidation stress, dry samples generally exhibited slightly higher cone resistance than saturated samples, whereas at the higher consolidation stress, no difference between dry and saturated conditions could be observed.

- Two anomalous samples tested dry at medium relative density exhibited way higher cone resistances than expected from published cone resistance-relative density relationships.

- The Young's modulus was observed to be proportional to steady-state cone resistance and independent whether samples were tested dry or saturated, being therefore considered as more robust soil property than relative density for cone resistance relationships. 
Acknowledgements We acknowledge Marc Huhndorf, Joann Schmid, and Wolfgang Schunn for technical assistance as well as Daniel A. Hepp and Dina Al-Sammarraie for scientific discussions on the paper. We further acknowledge Sergio Airoldi and Vicenzo Fioravante for their hospitality and for providing Ticino sand for our laboratory cone penetration tests. We thank three anonymous reviewers and Editorial Board member Gianvito Scaringi for providing their feedback on this manuscript.

Funding Open Access funding enabled and organized by Projekt DEAL. The present study was part of "Vibro-CPTu" (FKZ: 0325906 A), funded by the German Federal Ministry for Economic Affairs and Energy (BMWi) and supported by the MARUM-Center for Marine Environmental Sciences. This research was partly funded by MBIE Endeavour Fund (UOWX1903) and Marsden Fund (UOW1902).

Open Access This article is licensed under a Creative Commons Attribution 4.0 International License, which permits use, sharing, adaptation, distribution and reproduction in any medium or format, as long as you give appropriate credit to the original author(s) and the source, provide a link to the Creative Commons licence, and indicate if changes were made. The images or other third party material in this article are included in the article's Creative Commons licence, unless indicated otherwise in a credit line to the material. If material is not included in the article's Creative Commons licence and your intended use is not permitted by statutory regulation or exceeds the permitted use, you will need to obtain permission directly from the copyright holder. To view a copy of this licence, visit http://creativecommons.org/licenses/by/4.0/.

\section{References}

Almeida M, Jamiolkowski M, Peterson R (1991) Preliminary result of CPT tests in calcareous Quiou sand. In: Proceedings of the First International Symposium on Calibration Chamber Testing/ ISOCCTI, Potsdam, Germany. Elsevier Science Publishing Co, New York, pp: 41-53

Arroyo M, Butlanska J, Gens A, Calvetti F, Jamiolkowski M (2011) Cone penetration tests in a virtual calibration chamber. Géotechnique 61: 525-531. https://doi.org/10.1680/geot.9.P.067

ASTM D5778 (2012) Standard test method for electronic friction cone and piezocone penetration testing of soils. ASTM International, West Conshohocken, PA, United States. https://doi.org/10.1520/ D5778-12

ASTM D7181 (2020) Standard test method for consolidated drained triaxial compression test for soils. ASTM International, West Conshohocken, PA, United States. https://doi.org/10.1520/D718120

Baldi G, Bellotti R, Ghionna V, Jamiolkowski M, Pasqualini E (1981) Cone resistance of a dry medium sand. In: Proceedings of the 10th International Conference on Soil Mechanics and Foundation Engineering, Stockholm, Sweden. pp: 427-432

Baldi G, Bellotti R, Ghionna V, Jamiolkowski M, Pasqualine E (1982) Design parameters for sands from CPT. In: Proceedings of the Second European Symposium on Penetration Testing. Balkema, Amsterdam, pp 425-432

Bellotti R, Fretti C, Ghionna VN, Pedroni S (1992) Compressibility and crushability of sands at high stresses. In: Proceedings of the First International Symposium on Calibration Chamber Testing/ ISOCCT1. Elsevier Science Publishing Co, Potsdam, pp 79-90

Bonita JA (2000) The effects of vibration on the penetration resistance and pore water pressure in sands. PhD Thesis, Virginia Polytechnic Institute and State University
Butlanska J, Arroyo M, Gens A, O’Sullivan C (2014) Multi-scale analysis of cone penetration test (CPT) in a virtual calibration chamber. Canadian Geotechnical Journal 51:51-66. https://doi.org/10.1139/ cgj-2012-0476

Dai BB, Yang J, Zhou CY (2016) Observed effects of interparticle friction and particle size on shear behavior of granular materials. International Journal of Geomechanics 16:04015011. https://doi. org/10.1061/(ASCE)GM.1943-5622.0000520

Dano C, Ovalle C, Yin Z-Y, Daouadji A, and Hicher P-Y (2018) Behavior of granular materials affected by grain breakage. In: Nicot, F., and Millet, O. (ed) Advances in Multi-Physics and Multi-Scale Couplings in Geo-Environmental Mechanics. Elsevier, pp 95-132

DIN EN ISO 22476-1 (2013) Geotechnical investigation and testing field testing - part 1: electrical cone and piezocone penetration test (ISO 22476-1:2012 + Cor. 1:2013); German version EN ISO 22476-1:2012 + AC:2013. Beuth. https://doi.org/10.31030/ 2059678

Fioravante V, Giretti D (2015) Unidirectional cyclic resistance of Ticino and Toyoura sands from centrifuge cone penetration tests. Acta Geotechnica 11:953-968. https://doi.org/10.1007/s11440-0150419-3

Fleischer M, Kreiter S, Mörz T, Huhndorf M (2016) A small volume calibration chamber for cone penetration testing (CPT) on submarine soils. In: Lamarche, G. e. a. (ed) Submarine Mass Movements and their Consequences. Advances in Natural and Technological Hazards Research. Springer, Cham, pp 181-189

Gade V, Chauhan V, Dasaka S (2015) Assessment of pluviation method of sand bed preparation by miniature cone penetration. In: 50th Indian Geotechnical Conference, Pune, Maharashtra, India. pp: 1-7

Ghionna V, Jamiolkowski M (1991) A critical appraisal of calibration chamber testing of sands. In: Proceedings of the First International Symposium on Calibration Chamber Testing/ISOCCTI, Potsdam. Germany. Elsevier Science Publishing Co, New York, pp 13-37

Giretti D, Been K, Fioravante V, Dickenson S (2018) CPT calibration and analysis for a carbonate sand. Géotechnique 68:345-357. https://doi. org/10.1680/jgeot.16.P.312

Goodarzi M, Stähler FT, Kreiter S, Rouainia M, Kluger MO, Mörz T (2018) Numerical simulation of cone penetration test in a smallvolume calibration chamber: the effect of boundary conditions. In: Proceedings of the fourth international symposium on cone penetration testing. CRC Press, Delft, pp 309-315

Haiderali A, Nakashima M, Madabhushi S (2015) Cyclic lateral loading of monopiles for offshore wind turbines. In: Frontiers in Offshore Geotechnics III: Proceedings of the 3rd International Symposium on Frontiers in Offshore Geotechnics (ISFOG 2015), Taylor \& Francis Books Ltd, pp: 711-716.

Hamrock BJ, Schmid SR, Jacobson BO (2004) Fundamentals of fluid film lubrication. CRC press, Boca Raton

Hariprasad C, Rajashekhar M, Umashankar B (2016) Preparation of uniform sand specimens using stationary pluviation and vibratory methods. Geotechnical and Geological engineering 34:1909-1922. https://doi.org/10.1007/s10706-016-0064-0

Hryciw RD, Dowding CH (1987) Cone penetration of partially saturated sands. Geotechnical Testing Journal 10:135-141

Huang AB, Hsu HH (2005) Cone penetration tests under simulated field conditions. Géotechnique 55:345-354. https://doi.org/10.1680/geot. 2005.55.5.345

Jamiolkowski M, Lo Presti D, Manassero M (2003) Evaluation of relative density and shear strength of sands from CPT and DMT. In: Germaine, J., Sheahan, T., and Whitman, R. (ed) Soil behavior and soft ground construction. American Society of Civil Engineers, pp 201-238

Kulhawy FH, Mayne PW (1990) Manual on estimating soil properties for foundation design. Electric Power Research Inst., Palo Alto, CA 
(USA); Cornell Univ., Ithaca, NY (USA). Geotechnical Engineering Group, United States

Lagioia R, Sanzeni A, Colleselli F (2006) Air, water and vacuum pluviation of sand specimens for the triaxial apparatus. Soils and Foundations 46:61-67. https://doi.org/10.3208/sandf.46.61

Lunne T, Robertson P, Powell J (1997) Cone penetration testing in geotechnical practice. Blackie Academic \& Professional, United States and Canada

Mirghasemi A, Rothenburg L, Matyas E (2002) Influence of particle shape on engineering properties of assemblies of two-dimensional polygon-shaped particles. Géotechnique 52:209-217. https://doi. org/10.1680/geot.2002.52.3.209

Oldecop LA, Alonso E (2003) Suction effects on rockfill compressibility. Géotechnique 53:289-292. https://doi.org/10.1680/geot.2003.53.2. 289

Porcino D, Marcianò V (2010) Evaluating liquefaction resistance of a calcareous sand using the cone penetration test. In: Fifth International Conference on Recent Advances in geotechnical Earthquake Engineering and Soil Dynamics, pp: 1-9

Pournaghiazar M, Russell AR, Khalili N (2013) The cone penetration test in unsaturated sands. Géotechnique 63:1209-1220. https://doi.org/ 10.1680/geot.12.P.083

Robertson PK (2009) Interpretation of cone penetration tests - a unified approach. Canadian Geotechnical Journal 46:1337-1355. https:// doi.org/10.1139/t09-065

Robertson PK (2010) Estimating in-situ soil permeability from CPT \& CPTu. In: Proceedings of the 2nd International Symposium on Cone Penetration Testing, Huntington Beach, Ca, United States. pp: 1-8

Robertson PK, Campanella RG (1983) Interpretation of cone penetration tests. Part I: Sand. Canadian Geotechnical Journal 20:718-733. https://doi.org/10.1139/t83-078

Sadrekarimi A (2016) Evaluation of CPT-based characterization methods for loose to medium-dense sands. Soils and Foundations 56:460 472. https://doi.org/10.1016/j.sandf.2016.04.012

Schmertmann JH (1978) Guidelines for cone penetration test (performance and design). Federal Highway Administration, United States

Shaqour FM (2006) Cone penetration resistance of calcareous sand. Bulletin of Engineering Geology and the Environment 66:59-70. https://doi.org/10.1007/s10064-006-0061-2
Silva MF, White DJ, Bolton MD (2006) An analytical study of the effect of penetration rate on piezocone tests in clay. International Journal for Numerical and Analytical Methods in Geomechanics 30:501527. https://doi.org/10.1002/nag.490

Skinner A (1969) A note on the influence of interparticle friction on the shearing strength of a random assembly of spherical particles. Géotechnique 19:150-157

Stähler FT (2020) Cone penetration tests in a small volume calibration chamber - effects related to sand type, saturation state, cyclic preloading, vibratory penetration mode, and boundary condition. Ph.D. Thesis, University of Bremen

Stähler FT, Kreiter S, Goodarzi M, Al-Sammaraie D, Mörz T (2018a) Liquefaction resistance by static and vibratory cone penetration tests. In: Proceedings of the fourth international symposium on cone penetration testing. CRC Press, Delft, pp 592-598

Stähler FT, Kreiter S, Goodarzi M, Al-Sammarraie D, Stanski T, Mörz T (2018b) Influences on CPT-results in a small volume calibration chamber. In: Proceedings of China-Europe Conference on Geotechnical Engineering. Springer International Publishing, Vienna, pp 730-733. https://doi.org/10.1007/978-3-319-97112-4 163

Suzuki Y, Lehane B (2015) Analysis of CPT end resistance at variable penetration rates using the spherical cavity expansion method in normally consolidated soils. Computers and Geotechnics 69:141152. https://doi.org/10.1016/j.compgeo.2015.04.019

Tiwari B, Al-Adhadh AR (2014a) Influence of relative density on static soil-structure frictional resistance of dry and saturated sand. Geotechnical and Geological Engineering 32:411-427. https://doi. org/10.1007/s10706-013-9723-6

Tiwari B, and Al-Adhadh AR (2014b) Influence of void ratio on static soil-structure frictional resistance of dry and saturated sand. In: GeoCongress 2014: Geo-characterization and Modeling for Sustainability, pp: 1503-1510.

Yamashita S, Jamiolkowski M, Presti DCL (2000) Stiffness nonlinearity of three sands. Journal of Geotechnical and Geoenvironmental Engineering 126:929-938. https://doi.org/10.1061/(ASCE)10900241(2000)126:10(929) 